\title{
Trisomy 14 as a Sole Chromosome Abnormality Is Associated with Older Age, a Heterogenous Group of Myeloid Neoplasms with Dysplasia, and a Wide Spectrum of Disease Progression
}

\author{
Wei Cui, Carlos E. Bueso-Ramos, C. Cameron Yin, Jianlan Sun, Su Chen, \\ Ramya Muddasani, and Gary Lu \\ Department of Hematopathology, The University of Texas MD. Anderson Cancer Center, 1515 Holcombe Bouleuard, Unit 350, \\ Houston, TX 77030, USA \\ Correspondence should be addressed to Gary Lu, gglu@mdanderson.org
}

Received 7 September 2010; Revised 24 November 2010; Accepted 26 November 2010

Academic Editor: Lisa Wiesmuller

Copyright () 2010 Wei Cui et al. This is an open access article distributed under the Creative Commons Attribution License, which permits unrestricted use, distribution, and reproduction in any medium, provided the original work is properly cited.

\begin{abstract}
Trisomy 14 is a rare recurrent cytogenetic abnormality in myeloid neoplasms; however, its clinicopathologic features have not been well described. We report the clinicopathologic, immunophenotypic, and molecular genetic features of 16 cases of myeloid neoplasms with isolated trisomy 14 . Our results show that cases with isolated trisomy 14 encompass a heterogenous group of myeloid neoplasms including myelodysplastic syndrome (MDS, 44\%), myelodysplastic/myeloproliferative neoplasms (31\%), and acute myeloid leukemia (25\%). The patients are usually elder (median age 71 years), and there is a male predominance ( $82 \%)$. Multilineage dysplasia is noted in all cases. Oncogenic mutations of genes involved in cell proliferation and/or survival rarely occur. Compared with cases of MDS with diploid karyotype, patients of MDS with isolated trisomy 14 demonstrate a similar overall survival and rate of leukemia transformation.
\end{abstract}

\section{Introduction}

The occurrence of isolated gain of a chromosome is reported in $6-7 \%$ of human malignancies; the most common of which in myeloid neoplasms are chromosomes $8,9,13$, and 21 [1]. Trisomy $14(+14)$ as the sole cytogenetic abnormality is rather uncommon and has been reported in the setting of myeloid neoplasms [2-9]. Among the myeloid neoplasms, myelodysplastic syndrome (MDS) is the most common, followed by myelodysplastic/myeloproliferative neoplasms (MDS/MPN) and acute myeloid leukemia (AML) [2-9]. Chronic myelomonocytic leukemia (CMML) and atypical chronic myeloid leukemia, $B C R-A B L 1$ negative, are the two most common entities in the MDS/MPN group. The clinicopathologic features of myeloid neoplasms with isolated trisomy 14 has not been well described. The prognostic significance of isolated trisomy 14 also remains elusive.

In this study, we report the clinicopathologic, immunophenotypic and molecular genetic features of 16 cases of myeloid neoplasms associated with isolated trisomy 14, the largest series to date. In addition, the overall survival between MDS patients with isolated trisomy 14 and those with a diploid karyotype is compared.

\section{Materials and Methods}

2.1. Case Selection and Clinical Data. The study was conducted according to an institutional review board-approved laboratory protocol. Cases with isolated trisomy 14 in bone marrow were collected from the database of the Clinical Cytogenetic Laboratory at our institution between July 1, 1998 and January 31, 2009. For prognosis comparison, because diploid karyotype has been defined as a good risk prognostic indicator in MDS [10], a diagnosismatched group of 19 cases with MDS and a diploid karyotype was also collected from the same study period. Clinical data was obtained from review of the medical records. 
2.2. Morphologic Examination. We reviewed bone marrow core biopsy, clot, aspirate smears, and touch imprints in all cases. Decalcified core biopsy and aspirate clot were routinely processed and stained with hematoxylin and eosin (H\&E). Bone marrow cellularity was assessed in the core biopsy specimens. Differential 500-cell counts were performed on either touch imprints or aspirate smears stained with WrightGiemsa. Particular attention was paid to the presence of dysplasia in granulocytes, erythrocytes, and megakaryocytes. The percentages of blasts were recorded. The diagnoses of MDS, MDS/MPN, and AML were made based on the 2008 World Health Organization (WHO) classification [10]. All cases were independently reviewed by three hematopathologists.

2.3. Immunophenotypic Analysis. Immunophenotypic analysis by flow cytometry was performed on bone marrow aspirate specimens using an FACScan or FACSCalibur instrument (Becton-Dickinson Biosciences, San Jose, CA), as described previously [11]. The blast population was gated using right angle side scatter and CD45 expression. The panel of monoclonal antibodies included reagents specific for $\mathrm{CD} 2$, CD3, CD5, CD7, CD10, CD13, CD14, CD15, CD19, CD20, CD33, CD34, CD38, CD41, CD56, CD64, CD117, HLA-DR, $\mathrm{TdT}$, and myeloperoxidase (Becton-Dickinson Biosciences).

2.4. Conventional Cytogenetic and Fluorescence In Situ Hybridization Analyses. Conventional cytogenetic analysis was performed on metaphase cells prepared from bone marrow aspirate specimens cultured for 24-48 hours using standard techniques as described previously [12]. Giemsabanded metaphases were analyzed, and the results were reported using the International System for Human Cytogenetic Nomenclature, 2009.

Fluorescence in situ hybridization (FISH) analysis was performed on 2 cases with a questionable +14 clone on interphase nuclei using LSI IgH (mapped to 14q32) dual color, break apart probe (Vysis/Abbott Laboratories, Des Plaines, IL) to confirm the presence of trisomy 14 clone. Two hundred interphases were analyzed for each sample. The cutoff for the $\mathrm{IgH}$ triplication is $4.1 \%$. Results with three intact IgH signals confirm the presence of trisomy 14.

2.5. Molecular Analysis. Molecular studies for mutations in KIT (exons 8 and 17), KRAS and NRAS (codons 12, 13 and 61), FLT3 (internal tandem duplication (ITD) and codons 835/836), NPM1 (exon 12), and JAK2 (V617F) were performed as described previously [13]. DNA was extracted from peripheral blood or bone marrow aspirates using Autopure LS automated DNA extraction system (Qiagen, Valencia, CA) and was amplified by polymerase chain reaction (PCR) using gene specific primers. PCR products were then analyzed for mutations by Sanger sequencing using BigDye Terminator Cycle Sequencing reagents (Applied Biosystems, Carlsbad, CA) (KIT), pyrosequencing using PSQ96 HS System (Qiagen) (KRAS, NRAS, JAK2), and DNA fragment size analysis using 3130 Genetic Analyzer (Applied Biosystems) (FLT3 and NPM1).
2.6. Statistical Analysis. By using the Kaplan-Meier method, we calculated the overall survival of patients with myeloid neoplasms and isolated trisomy 14. We further compared the overall survival for patients with MDS and isolated trisomy 14 with that for patients with MDS and diploid karyotype using double-sided Log-rank test. Chi-Square test was utilized to compare rate of progression to AML between patients with MDS and isolated trisomy 14 and patients with MDS and diploid karyocype. Results were considered statistically significant when $P$ value is $<.05$ on both sides. GraphPad Prism 5 (GraphPad Software, La Jolla, CA) was used for statistical analysis.

\section{Results}

3.1. Classification of Cases with Isolated Trisomy 14. We identified a total of 16 patients with isolated trisomy 14 from July 1, 1998 to January 31, 2009, including 7 cases of MDS, 5 cases of MDS/MPN, and 4 cases of AML. The median age was 71 years (range, 51-86 years) with a male to female ration of $12: 4$. The clinical and morphologic features as well as conventional cytogenetic results are summarized in Tables 13 and described separately.

3.2. Myelodysplastic Syndromes with Isolated Trisomy 14. A diagnosis of MDS was made in 7 patients (Table 1). The median age of patients in this subgroup was 73 years (range, 63-79), and the male to female ratio was 6:1. At presentation in our institution, all patients had anemia (median hemoglobin, $10.0 \mathrm{~g} / \mathrm{dL}$; range, $8.1-10.8 \mathrm{~g} / \mathrm{dL}$; reference range, $14.0-16.0 \mathrm{~g} / \mathrm{dL}$ for men, $12.0-14.0 \mathrm{~g} / \mathrm{dL}$ for women). Three patients had leukopenia (median white blood cell count, $4.210^{9} / \mathrm{L}$; range, 1.6-8.8 $10^{9} / \mathrm{L}$; reference range, $4.0-11.010^{9} / \mathrm{L}$ ), and 4 patients had thrombocytopenia (median platelet count, $7910^{9} / \mathrm{L}$; range, 23-465 10 $/ \mathrm{L}$; reference range, $140-44010^{9} / \mathrm{L}$ ).

The bone marrow cellularity ranged from 15 to $95 \%$ (median, 65\%). Trilineage dysplasia was present in all 7 cases. The blast count ranged from 1 to $18 \%$ (median, $8 \%$ ). The cases were classified as refractory anemia with excess blasts (RAEB) type 2 (RAEB-2, $n=2)$, RAEB- $1(n=2)$, refractory anemia with ring sideroblasts (RARS, $n=2$ ), and refractory cytopenia with multilineage dysplasia (RCMD, $n=1$ ), based on the WHO classification. Using the International Prognostic Scoring System (IPSS) [10], the MDS cases were considered as high $(n=2)$, intermediate-2 $(n=1)$, and intermediate-1 $(n=4)$ risk groups.

3.3. Myelodysplastic/Myeloproliferative Neoplasms with Isolated Trisomy 14. Five patients had a diagnosis of MDS/MPN (Table 2). The median age of patients in this subgroup was 72 years (range, 51-86), and the male to female ratio was $2: 3$. Anemia was present in 4 patients (median hemoglobin, $10.8 \mathrm{~g} / \mathrm{dL}$; range, $8.8-13.7 \mathrm{~g} / \mathrm{dL}$; reference range, $14.0-16.0 \mathrm{~g} / \mathrm{dL}$ for men, $12.0-14.0 \mathrm{~g} / \mathrm{dL}$ for women). Four had leukocytosis (median white blood cell count, $14.810^{9} / \mathrm{L}$; range, 7.6-19.2 10 $/ \mathrm{L}$; reference range, 4.0-11.0 10 $/ \mathrm{L}$ ), and 
TABLe 1: Clinical, morphologic, and cytogenetic characteristics of patients with myelodysplastic syndrome and isolated trisomy 14.

\begin{tabular}{|c|c|c|c|c|c|c|c|c|c|c|}
\hline $\begin{array}{l}\text { Age } \\
(\mathrm{Y})\end{array}$ & Sex & $\begin{array}{l}\text { WBC } \\
\left(10^{9} / \mathrm{L}\right)\end{array}$ & $\begin{array}{c}\mathrm{Hb} \\
(\mathrm{g} / \mathrm{dL})\end{array}$ & $\begin{array}{l}\text { Platelet } \\
\left(10^{9} / \mathrm{L}\right)\end{array}$ & $\begin{array}{l}\text { WHO } \\
\text { classification }\end{array}$ & Karyotype & $\begin{array}{c}\text { Cellularity } \\
(\%)\end{array}$ & $\begin{array}{c}\text { Blast } \\
(\%)\end{array}$ & $\begin{array}{l}\text { Trilineage } \\
\text { dysplasia }\end{array}$ & $\begin{array}{l}\text { IPSS } \\
\text { score }\end{array}$ \\
\hline 79 & M & 4.2 & 10.1 & 79 & RAEB-1 & $47, \mathrm{XY},+14[3] / 46, \mathrm{XY}[14]$ & 90 & 8 & Yes & 1.0 \\
\hline 79 & M & 1.6 & 9.2 & 75 & RAEB-2 & $47, \mathrm{XY},+14[8] / 46, \mathrm{XY}[12]^{*}$ & 15 & 18 & Yes & 2.5 \\
\hline 75 & $\mathrm{~F}$ & 4.5 & 11.2 & 38 & RAEB-1 & $47, \mathrm{XX},+14[3] / 46, \mathrm{XX}[14]^{*}$ & 65 & 13 & Yes & 2.0 \\
\hline 70 & M & 3.4 & 8.1 & 23 & RAEB-2 & $46, \mathrm{XX}, \mathrm{i}(14)(\mathrm{q} 10)[8]$ & 90 & 13 & Yes & 2.5 \\
\hline 73 & M & 3.9 & 10.0 & 351 & RARS & $\begin{array}{l}46, \mathrm{X},-\mathrm{Y},+14[3] / 45, \mathrm{X},-\mathrm{Y}[2] / \\
46, \mathrm{XY}[15]^{*}\end{array}$ & 35 & 4 & Yes & 1.0 \\
\hline 63 & M & 8.8 & 10.8 & 465 & RARS & $\begin{array}{l}46, \mathrm{XY}, \mathrm{i}(14)(\mathrm{q} 10)[5] / 46, \mathrm{XY} \\
{[15]^{*}}\end{array}$ & 60 & 2 & Yes & 0.5 \\
\hline 68 & M & 6.0 & 8.5 & 156 & RCMD & $46, X Y, i(14)(q 10)[16]$ & 95 & 1 & Yes & 0.5 \\
\hline
\end{tabular}

* Diploid karyotype at time of initial diagnosis.

Y: years; M: male; F: female; WBC: white blood cell; Hb: hemoglobin; RAEB: refractory anemia with excess blasts; RARS: refractory anemia with ring sideroblasts; RCMD: refractory cytopenia with multilineage dysplasia; IPSS: international prognostic scoring system.

TABLE 2: Clinical, morphologic, and cytogenetic characteristics of patients with myelodysplastic/myeloproliferative neoplasms and isolated trisomy 14 .

\begin{tabular}{|c|c|c|c|c|c|c|c|c|c|c|}
\hline $\begin{array}{l}\text { Age } \\
(\mathrm{Y})\end{array}$ & Sex & $\begin{array}{c}\text { WBC } \\
\left(10^{9} / \mathrm{L}\right)\end{array}$ & $\begin{array}{l}\mathrm{Hb} \\
(\mathrm{g} / \mathrm{dL})\end{array}$ & $\begin{array}{l}\text { Platelet } \\
\left(10^{9} / \mathrm{L}\right)\end{array}$ & $\begin{array}{l}\text { WHO } \\
\text { classification }\end{array}$ & Karyotype & $\begin{array}{c}\text { Cellularity } \\
(\%)\end{array}$ & Blast (\%) & $\begin{array}{l}\text { Trilineage } \\
\text { dysplasia }\end{array}$ & IPSS score \\
\hline 68 & M & 14.8 & 13.7 & 626 & CMML-1 & $47, \mathrm{XY},+14[16]$ & 85 & 8 & Yes & 1.0 \\
\hline 72 & M & 18.6 & 8.8 & 198 & CMML-1 & $47, \mathrm{XY},+14[16]$ & 90 & 2 & Yes & 0.5 \\
\hline 86 & $\mathrm{~F}$ & 11.3 & 10.8 & 171 & CMML-1 & $47, \mathrm{XX},+14[16]$ & 95 & 9 & Yes & 1.0 \\
\hline 51 & $\mathrm{~F}$ & 7.6 & 12.3 & 160 & CMML-2 & $46, \mathrm{XX}, \mathrm{i}(14)(\mathrm{q} 10)[16]$ & 35 & 17 & Yes & 2.0 \\
\hline 77 & $\mathrm{~F}$ & 19.2 & 9.7 & 291 & MDS/MPN-U & $\begin{array}{l}47, \mathrm{XX},+14[14] / 46, \mathrm{XX} \\
{[3]^{*}}\end{array}$ & 100 & 6 & Yes & 1.0 \\
\hline
\end{tabular}

* Unknown karyotype at time of initial diagnosis.

Y: years; M: male; F: female; WBC: white blood cell; Hb: hemoglobin; CMML: chronic myelomonocytic leukemia; MDS/MPN-U: myelodysplastic/myeloproliferative neoplasm, unclassifiable; IPSS: international prognostic scoring system.

one had thrombocytosis (median platelet count, $19810^{9} / \mathrm{L}$; range, $160-62610^{9} / \mathrm{L}$; reference range, $140-44010^{9} / \mathrm{L}$ ).

The bone marrow cellularity ranged from 35 to $100 \%$ (median, 95\%). Trilineage dysplasia was present in all 5 cases. The blast count ranged from 2 to $17 \%$ (median, $8 \%$ ). The cases were classified as chronic myelomonocytic leukemia (CMML) type $1(n=3)$, CMML-2 $(n=1)$, and MDS/MPN, unclassifiable (MDS/MPN-U, $n=1$ ), based on the WHO classification. Using the International Prognostic Scoring System (IPSS) [10], the MDS/MPN cases were considered as intermediate-2 $(n=1)$ and intermediate-1 $(n=4)$ risk groups.

3.4. Acute Myeloid Leukemia with Isolated Trisomy 14. Four patients were diagnosed with AML (Table 3). The median age of patients in this subgroup was 63 years (range, 5770 ), and the male to female ratio was 4:0. At presentation to our institution, all patients had anemia (median hemoglobin, $9.9 \mathrm{~g} / \mathrm{dL}$; range, $8.1-10.3 \mathrm{~g} / \mathrm{dL}$; reference range, $14.0-16.0 \mathrm{~g} / \mathrm{dL}$ for men, $12.0-14.0 \mathrm{~g} / \mathrm{dL}$ for women). Two had leucopenia, and one had leukocytosis (median white blood cell count, $3.210^{9} / \mathrm{L}$; range, $1.1-16210^{9} / \mathrm{L}$; reference range, $4.0-11.010^{9} / \mathrm{L}$ ), and 3 had thrombocytopenia (median platelet count, $6110^{9} / \mathrm{L}$; range, 56-305 10\%/L; reference range, $140-44010^{9} / \mathrm{L}$ ).
The bone marrow cellularity ranged from 25 to $95 \%$ (median, 70\%). Trilineage dysplasia was present in all 4 cases. The blast count ranged from 30 to $60 \%$ (median, 44\%). Three cases were classified as AML with maturation, and the other case was classified as AML without maturation.

3.5. Immunophenotypic Features. Flow cytometry immunophenotyping was performed in 12 cases with a blast count greater than 5\%. In all cases assessed, the blasts demonstrated myeloid immunophenotype positive for CD13 (12/12), CD33 (12/12), CD38 (12/12), CD117 (12/12), HLADR (12/12), CD34 (11/12), myeloperoxidase (10/12), TdT (3/12), CD7 (2/12), CD64 (2/12), and CD14 (1/12), and negative for the rest of the markers assessed.

3.6. Cytogenetic Results. Five cases had a clone with an isochromosome $14 \mathrm{q}$, and the remainder had a typical trisomy 14 clone (Tables 1-3). Chromosome 14 is an acrocentric chromosome. An isochromosome for 14q, i(14)(q10), is formed by rearrangement of two homologous long arms of chromosome 14 that are mirror image of each other [18]. The short arm of chromosome 14 contains repetitive ribosomal DNA; the loss of which is generally considered inconsequential [15]. Therefore, the presence of an acquired $\mathrm{i}(14)$ (q10) in addition to a normal copy of chromosome 14 
TABLe 3: Clinical, morphologic, and cytogenetic characteristics of patients with acute myeloid leukemia and isolated trisomy 14.

\begin{tabular}{|c|c|c|c|c|c|c|c|c|c|}
\hline $\begin{array}{l}\text { Age } \\
(\mathrm{Y})\end{array}$ & Sex & $\begin{array}{l}\text { WBC } \\
\left(10^{9} / \mathrm{L}\right)\end{array}$ & $\begin{array}{c}\mathrm{Hb} \\
(\mathrm{g} / \mathrm{dL})\end{array}$ & $\begin{array}{l}\text { Platelet } \\
\left(10^{9} / \mathrm{L}\right)\end{array}$ & WHO classification & Karyotype & $\begin{array}{c}\text { Cellularity } \\
(\%)\end{array}$ & $\begin{array}{c}\text { Blast } \\
(\%)\end{array}$ & $\begin{array}{l}\text { Trilineage } \\
\text { dysplasia }\end{array}$ \\
\hline 70 & M & 4.3 & 10.3 & 56 & AML with maturation & $\begin{array}{l}47, \mathrm{XY}, \mathrm{i}(14)(\mathrm{q} 10)[2] / 46, \mathrm{XY} \\
{[17]^{*}}\end{array}$ & 55 & 26 & Yes \\
\hline 61 & M & 162 & 8.1 & 63 & AML with maturation & $47, \mathrm{XY},+14[16]$ & 95 & 60 & Yes \\
\hline 57 & $\mathrm{M}$ & 1.1 & 9.7 & 59 & $\begin{array}{l}\text { AML without } \\
\text { maturation }\end{array}$ & $47, \mathrm{XY},+14[2] / 46, \mathrm{XY}[17]^{*}$ & 25 & 50 & Yes \\
\hline 65 & M & 2.1 & 10.1 & 305 & AML with maturation & $47, \mathrm{XY},+14[16]$ & 85 & 37 & Yes \\
\hline
\end{tabular}

* Abnormal clone confirmed by FISH.

Y: years; M: male; F: female; WBC: white blood cell; Hb: hemoglobin.

contains essentially the same genomic material as trisomy 14 , and cases with $\mathrm{i}(14)$ (q10) are also included in this study.

Trisomy 14 was detected at initial diagnosis of all AML, 4 of $5 \mathrm{MDS} / \mathrm{MPN}$, and 3 of 7 MDS cases. In the other 4 MDS cases, trisomy 14 occurred at 4, 5, 13, and 40 months after initial diagnosis, respectively. In 1 case of MDS/MPN-U, the initial karyotype was unknown, and the trisomy 14 was identified when the patient presented to our institution 30 months after initial diagnosis. Of the 16 patients, 8 also had a diploid clone. There was no evidence of clonal evolution in any of the 16 cases, even during the course of disease progression or leukemic transformation.

Fluorescence in situ hybridization (FISH) analysis was performed using LSI IgH (mapped to 14q32) dual color, break apart probe in 2 cases of AML that showed +14 in two metaphases by conventional cytogenetics analysis, and the FISH results confirmed the presence of trisomy 14 clone in both cases (Table 3 ).

3.7. Mutational Status of Selected Molecular Markers. Analyses on Class I mutations in KIT, RAS, FLT3, NPM1, and $J A K 2$ genes that affect cell proliferation and/or survival were performed in a subset of the cases. As shown in Table 4, FLT3-ITD was identified in 1 case of MDS and 1 case of AML, whereas KRAS mutation was found in 1 MDS case and NRAS mutation was present in 1 CMML-2 case. No other mutations were detected in the rest of the patients. The MDS patient who had FLT3-ITD mutation at initial presentation subsequently developed AML, whereas the MDS patient acquired KRAS mutation at the time of AML transformation. The patient with CMML-2 and an NRAS mutation had persistent disease at the last follow-up 28 months after initial diagnosis.

3.8. Survival, Clinical Outcome and Acute Leukemic Transformation in Patients with Isolated Trisomy 14. All patients were treated with chemotherapy. With a median follow-up of 21 months (range, 2-154 months), 11 patients died of disease, and 5 patients had persistent disease. The overall survival and rate of acute leukemic transformation for the three groups of patients are illustrated in Table 5 and Figure 1. The median survival was 28 months, 31.5 months, and 9 months for patients with MDS, MDS/MPN, and AML, respectively. Three of $7(43 \%)$ patients with MDS and 1 of $5(20 \%)$
TABLE 4: Class I mutation status in patients with isolated trisomy 14.

\begin{tabular}{lccc}
\hline Genes & MDS & MDS/MPN & AML \\
\hline FLT3 & $1 / 6$ & $0 / 3$ & $1 / 3$ \\
NPM1 & $0 / 5$ & $0 / 3$ & $0 / 3$ \\
C-KIT & $0 / 4$ & $0 / 3$ & $0 / 3$ \\
RAS & $1 / 7$ & $1 / 4$ & $0 / 3$ \\
$J A K 2$ & N/A & $0 / 2$ & N/A \\
\hline
\end{tabular}

MDS: myelodysplastic syndrome; MDS/MPN: myelodysplastic/myeloproliferative neoplasms; AML: acute myeloid leukemia; N/A: not applicable.

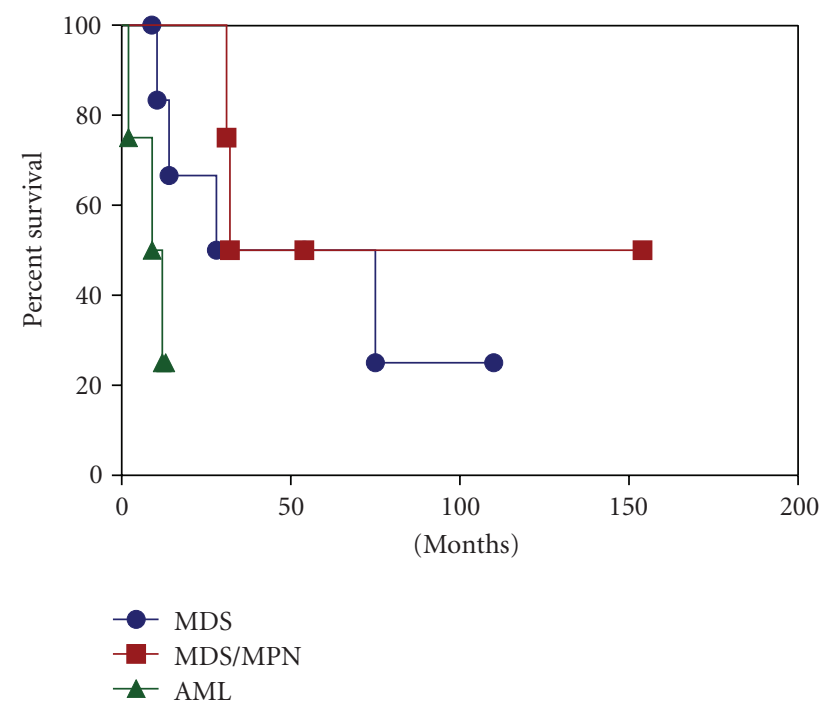

Figure 1: Overall survival of patients with myeloid neoplasms associated with isolated trisomy 14 .

patients with MDS/MPN developed AML with a median interval of 18 months (range, 4-66 months).

3.9. Comparison between MDS Cases with Isolated Trisomy 14 and MDS Cases with Diploid Karyotype. We compared major clinicopathologic and molecular genetic features between the trisomy 14 MDS cases $(n=7)$ and diploid MDS cases $(n=19)$ (Table 6 and Figure 2). Similar to cases with isolated trisomy 14, the frequency of Class I mutations in KIT, 
TABLE 5: Median survival and disease progression in patients with isolated trisomy 14.

\begin{tabular}{lccc}
\hline Features & MDS $(n=7)$ & MDS/MPN $(n=5)$ & AML $(n=4)$ \\
\hline Median survival (range) (month) & $28(10.5-75)$ & $31.5(31-32)$ & $9(2-12)$ \\
Leukemic transformation & $43 \%$ & $20 \%$ & N/A \\
Median interval of disease progression (month) & 7.75 & 29 & N/A \\
\hline
\end{tabular}

MDS: myelodysplastic syndrome; MDS/MPN: myelodysplastic/myeloproliferative neoplasms; AML: acute myeloid leukemia; N/A: not applicable.

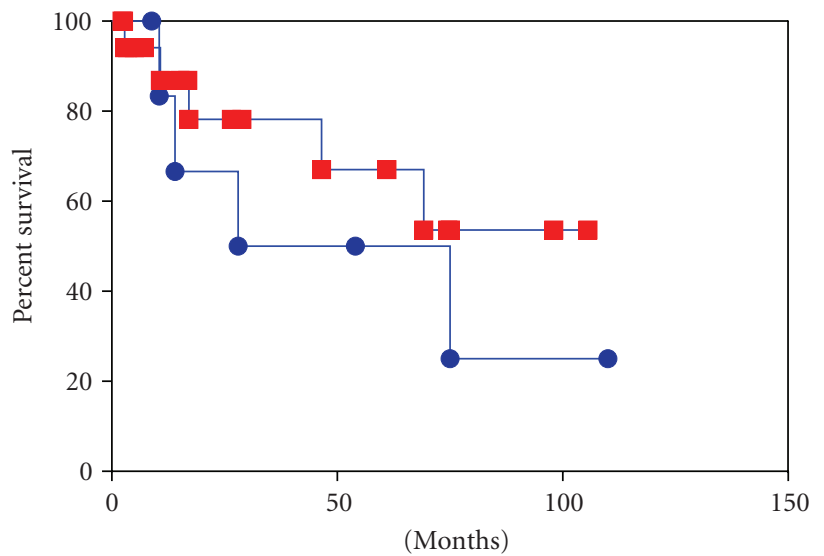

Trisomy 14

Diploid w/o transplant

FIGURE 2: Overall survival of patients with myelodysplastic syndrome and trisomy 14 versus diploid karyotype.

RAS, FLT3, and NPM1 was low in MDS cases with diploid karyotype. Two diploid MDS cases had a gene mutation, one in FLTT3 and the other in KRAS. No mutation was noted in KIT or NPM1 gene. The median overall survival was 28 months and 14.5 months for cases with isolated trisomy 14 and those with diploid karyotype, respectively. Three of 7 patients with trisomy 14 and 4 of 19 patients with diploid karyotype transformed to acute myeloid leukemia. However, no statistically significant differences were observed in overall survival $(P=.53$, Log-rank test $)$ and rate of leukemic transformation between the two groups $(P=.26$, ChiSquare test).

\section{Discussion}

Trisomy 14 as a sole chromosome abnormality is a rare nonrandom cytogenetic abnormality in myeloid neoplasms [19]. In review of the literature [2-9], a total of 75 cases of myeloid neoplasms with isolated trisomy 14 have been reported. However, the clinicopathologic features and prognostic significance of trisomy 14 are not well described. We therefore report clinicopathologic, immunophenotypic, and molecular genetic features in 16 cases of myeloid neoplasms with isolated trisomy 14 . In addition, we compare overall survival and rate of leukemic transformation between MDS cases with isolated trisomy 14 and MDS cases with a diploid karyotype.
The clinical features of cases with isolated trisomy 14 in our study are similar to those that have been reported previously in the literature. The median age of the reported cases was 70.5 years, whereas the median age in our study was 71 years, suggesting that patients with myeloid neoplasms and isolated trisomy 14 are usually elderly. In addition, we noted a male predominance with a male to female ration of $12: 4$. Hematological features in those patients with trisomy 14 described previously included monocytosis and relatively preserved platelet count $[5,7,8,14,17]$. Absolute monocytosis was present in 4 cases of CMML and 1 case of RAEB-2 in our cohort. Platelet count was well preserved in our series with a median of $158 \mathrm{~K} / \mathrm{uL}$ and a range of $23-626 \mathrm{~K} / \mathrm{uL}$. This is in keeping with the blood cell count reported previously.

Similar to the cases reported previously, our cases with isolated trisomy 14 encompassed a spectrum of myeloid malignancies including MDS, MDS/MPN, and AML. Additionally, in our study, MDS and MDS/MPN cases had an initial IPSS score in the range of intermediate-1 to high risk group, indicating that cases of MDS and MDS/MPN with isolated trisomy 14 are heterogenous diseases. Morphologically, all cases showed significant evidence of multilineage dysplasia, and most cases showed increased myeloblasts, supporting that these neoplastic processes affect a multipotent myeloid precursor.

Trisomy 14 was identified at initial diagnosis in most of our cases, suggesting that this abnormality may represent an early event in leukemogenesis. Emerging new clone with $\operatorname{del}(20 \mathrm{q})$ was previously reported in one MDS patient with isolated +14 during disease progression [5]. Toze et al. also showed an acquired trisomy 21 in an AML patient with isolated +14 during disease relapse [8]. However, no evidence of clonal evolution was observed in any of our patients during disease progression or leukemic transformation, which may be related to different patient population and different treatment strategy. Furthermore, $50 \%$ of patients in our study presented with a normal diploid cell line. This is in accordance with previously reported cases $[7,8]$.

The acquisition of additional genetic mutations may contribute to disease progression or leukemic transformation. Activating mutations in tyrosine kinases, FLT3, KIT, and $J A K 2$, as well as those in RAS and NPM1, confer proliferation and/or survival advantage to hematopoietic progenitors in corporation with loss-of-function of hematopoietic transcription factors [19]. Shih et al. [20] have shown that acquisition of FLT3 or $N$-RAS mutations is frequently associated with progression of MDS to AML. In our study, Class I mutation was present in only four patients including two MDS patients who eventually evolved into AML. 
TABLE 6: Clinical data for patients with myelodysplastic syndrome and isolated trisomy 14 or diploid karyotype.

\begin{tabular}{lccccccc}
\hline \multirow{2}{*}{ Group } & \multicolumn{2}{c}{ Sex } & \multicolumn{2}{c}{ Age (year) } & \multicolumn{2}{c}{ OS (month) } \\
& M & F & Median & Range & Median & Range & Leukemictransformation \\
\hline Diploid $(n=19)$ & 12 & 7 & 66 & $38-84$ & 14.5 & $0.6-129.5$ & 4 \\
$+14(n=7)$ & 6 & 1 & 73 & $63-79$ & 28.0 & $8.9-110.0$ & 3 \\
\hline
\end{tabular}

M: male; F: female; Y: years; OS: overall survival.

The other one patient acquired Class I mutation during disease progression. These findings suggest that trisomy 14 by itself may play an essential role in the initiation of these neoplastic processes. It has been suggested that dosage effect of extra copy of genes is potentially associated with cell proliferation [16]. FOS and AKT1 are the oncogenes mapped to $14(\mathrm{q} 21-\mathrm{q} 31)$ and $14(\mathrm{q} 32)$, respectively [8]. Increased FOS expression has been identified in AML, especially recurrent AML and familial MDS [21, 22]. Constitutively activated AKT1 in mice can induce MPN, T-cell lymphoma, or AML [23]. Furthermore, Jagged-2 (JAG2) (mapped to 14q32), a Notch ligand, has been found to be overexpressed in leukemic stem cells (LSCs) and inhibition of Jagged-2 can lead to suppression of LSC growth in colony formation assays [24].

No prior studies regarding the prognostic significance of trisomy 14 in myeloid malignancy have been reported. By comparing cases of MDS with isolated trisomy 14 and those with a diploid karyotype, our study demonstrated that MDS patients with isolated trisomy 14 had a similar overall survival and rate of leukemic transformation to those with a diploid karyotype. It is wellrecognized that cases of MDS with diploid karyotype represent a heterogenous group of diseases. Similarly, cases with isolated trisomy 14 are heterogenous and may encompass a spectrum of diseases with different molecular abnormalities.

In summary, we demonstrate that isolated trisomy 14 is associated with a variety of myeloid neoplasms with dysplasia and often occurs in older patients. Class I mutations are uncommon. Patients with MDS and isolated +14 have similar overall survival and rate of leukemic transformation as compared with MDS patients with diploid karyotype.

\section{References}

[1] S. Heim and F. Mitelman, Cancer Cytogenetics: Chromosomal and Molecular Genetic Aberrantions of Tumor Cells, Wiley-Liss, New York, NY, USA, 3rd edition, 2009.

[2] M. G. Boavida, P. Ambrósio, D. Dhermy, C. Silva, and M. E. Correia, "Isochromosome 14q in refractory anemia," Cancer Genetics and Cytogenetics, vol. 97, no. 2, pp. 155-156, 1997.

[3] O. A. Haas, U. Jager, P. Ambros, and I. Pabinger, "Trisomy 14 in refractory anemia with excess of blasts in transformation," Cancer Genetics and Cytogenetics, vol. 29, no. 2, pp. 315-318, 1987.

[4] Y. M. Horton and P. R. E. Johnson, "Trisomy 14 in myeloid malignanciesreport of two cases and review of the literature," Cancer Genetics and Cytogenetics, vol. 124, no. 2, pp. 172-174, 2001.

[5] M. Mancini, M. Cedrone, M. Nanni et al., "Trisomy 14 in hematologic diseases: another non-random abnormality within myeloid proliferative disorders," Cancer Genetics and Cytogenetics, vol. 66, no. 1, pp. 39-42, 1993.

[6] F. Mertens, B. Johansson, S. Heim et al., "Trisomy 14 in atypical chronic myeloid leukemia," Leukemia, vol. 4, no. 2, pp. 117-120, 1990.

[7] K. S. Reddy, "Trisomy 14 and leukemia," Cancer Genetics and Cytogenetics, vol. 106, no. 2, pp. 144-151, 1998.

[8] C. L. Toze, M. J. Barnett, S. C. Naiman, and D. E. Horsman, "Trisomy 14 is a non-random karyotypic abnormality associated with myeloid malignancies," British Journal of Haematology, vol. 98, no. 1, pp. 177-185, 1997.

[9] P. Tumewu and G. Royle, "Myelodysplastic syndrome and trisomy 14q," Cancer Genetics and Cytogenetics, vol. 64, no. 1, pp. 91-92, 1992.

[10] S. H. Swerdlow, E. Campo, E. S. Harris et al., WHO Classification of Tumours of Haematopoietic and Lymphoid Tissues, IARC Press, Lyon, France, 2008.

[11] C. C. Yin, P. Lin, D. A. Carney et al., "Chronic lymphocytic leukemia/small lymphocytic lymphoma associated with IgM paraprotein: a clinicopathologic study of 26 cases," American Journal of Clinical Pathology, vol. 123, no. 4, pp. 594-602, 2005.

[12] M. Onciu, E. Schlette, L. J. Medeiros, L. V. Abruzzo, M. Keating, and R. Lai, "Cytogenetic findings in mantle cell lymphoma: cases with a high level of peripheral blood involvement have a distinct pattern of abnormalities," American Journal of Clinical Pathology, vol. 116, no. 6, pp. 886-892, 2001.

[13] W. Chen, S. Konoplev, L. J. Medeiros et al., "Cuplike nuclei (prominent nuclear invaginations) in acute myeloid leukemia are highly associated with FLT3 internal tandem duplication and NPM1 mutation," Cancer, vol. 115, no. 23, pp. 5481-5489, 2009.

[14] H. W. Liu, K. W. Lie, and L. C. Chan, "Isochromosome 14q and leukemia with dysplastic features," Cancer Genetics and Cytogenetics, vol. 64, no. 1, pp. 97-98, 1992.

[15] A. S. Henderson, D. Warburton, and K. C. Atwood, "Location of ribosomal DNA in the human chromosome complement," Proceedings of the National Academy of Sciences of the United States of America, vol. 69, no. 11, pp. 3394-3398, 1972.

[16] S. Heim and F. Mitelman, "Numerical chromosome aberrations in human neoplasia," Cancer Genetics and Cytogenetics, vol. 22, no. 2, pp. 99-108, 1986.

[17] P. H. Pinkerton, B. London, I. D. Dube, and J. S. Senn, "Trisomy 14q in myelodysplastic syndromes," Cancer Genetics and Cytogenetics, vol. 49, no. 1, pp. 113-116, 1990.

[18] J. Welborn, "Acquired Robertsonian translocations are not rare events in acute leukemia and lymphoma," Cancer Genetics and Cytogenetics, vol. 151, no. 1, pp. 14-35, 2004.

[19] L. M. Kelly and D. G. Gilliland, "Genetics of myeloid leukemias," Annual Review of Genomics and Human Genetics, vol. 3, pp. 179-198, 2002.

[20] L. Y. Shih, C. F. Huang, P. N. Wang et al., "Acquisition of FLT3 or N-ras mutations is frequently associated with progression of myelodysplastic syndrome to acute myeloid leukemia," Leukemia, vol. 18, no. 3, pp. 466-475, 2004. 
[21] A. Pradhan, A. Mijovic, K. Mills et al., "Differentially expressed genes in adult familial myelodysplastic syndromes," Leukemia, vol. 18, no. 3, pp. 449-459, 2004.

[22] P. B. Staber, W. Linkesch, D. Zauner et al., "Common alterations in gene expression and increased proliferation in recurrent acute myeloid leukemia," Oncogene, vol. 23, no. 4, pp. 894-904, 2004.

[23] M. G. Kharas, R. Okabe, J. J. Ganis et al., "Constitutively active AKT depletes hematopoietic stem cells and induces leukemia in mice," Blood, vol. 115, no. 7, pp. 1406-1415, 2010.

[24] H. Gal, N. Amariglio, L. Trakhtenbrot et al., "Gene expression profiles of AML derived stem cells; similarity to hematopoietic stem cells," Leukemia, vol. 20, no. 12, pp. 2147-2154, 2006. 

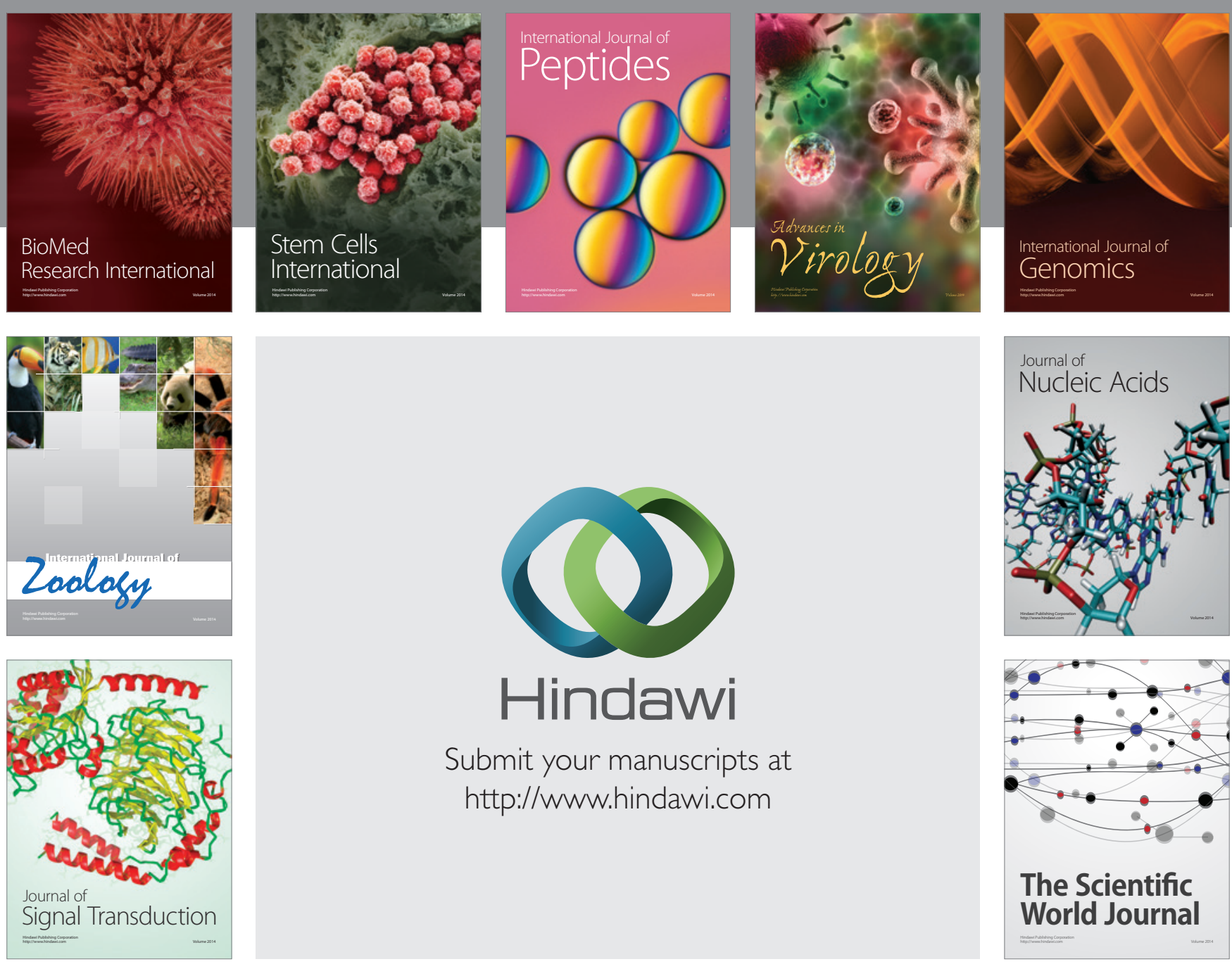

Submit your manuscripts at

http://www.hindawi.com
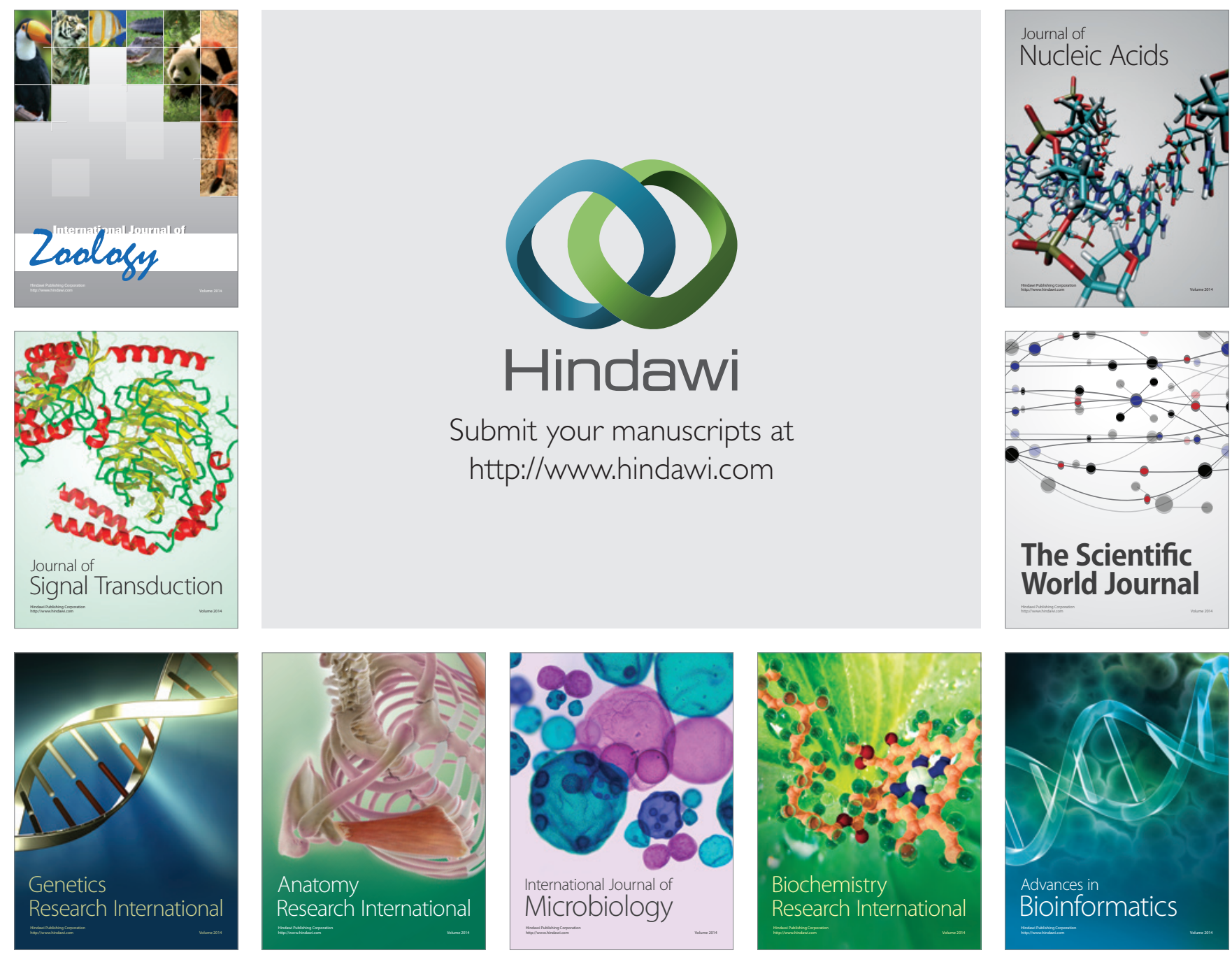

The Scientific World Journal
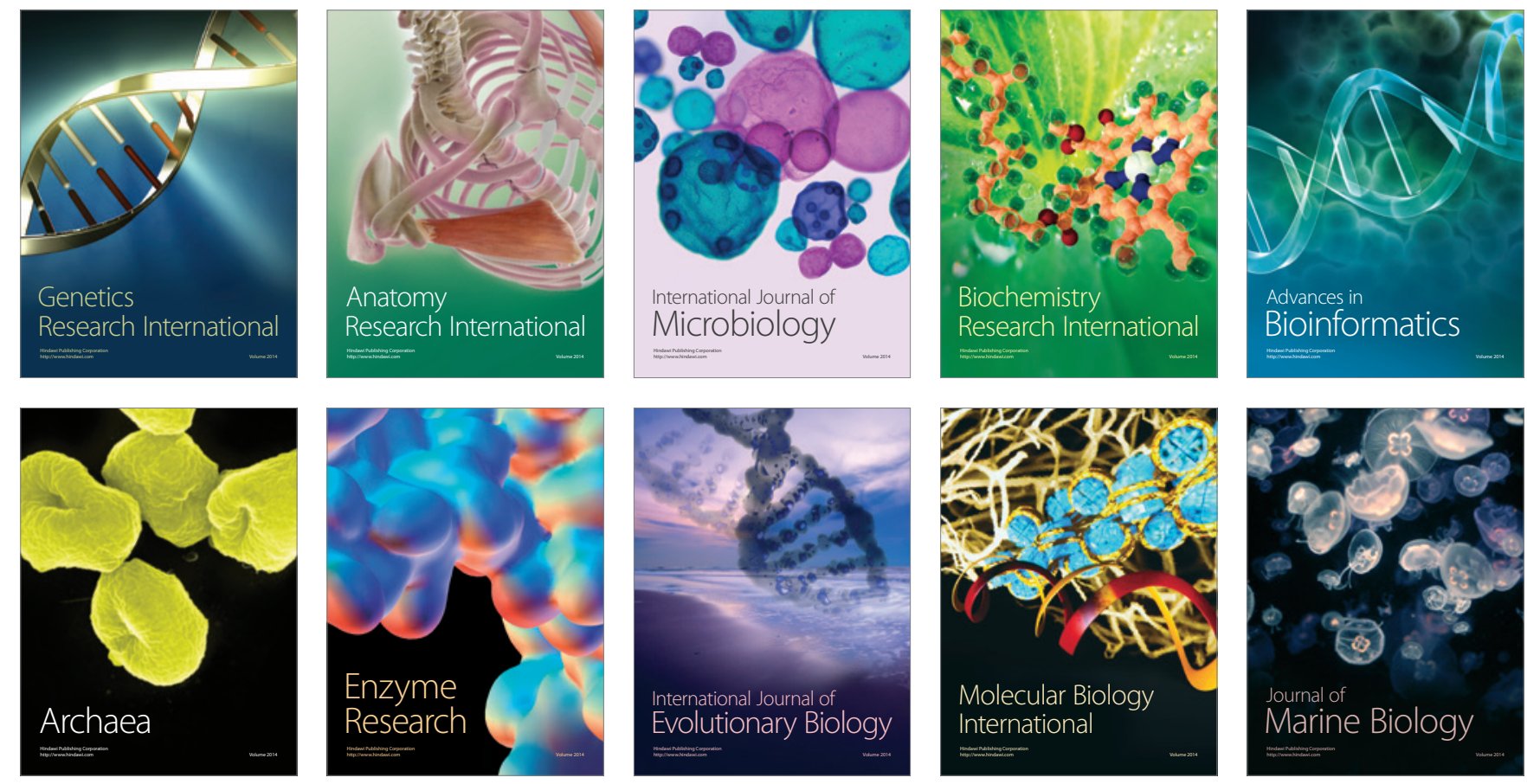